ENTREVISTA

\title{
ANTROPOLOGIA COM EMOÇÃO
}

Catherine Lutz

Catherine Lutz aceitou ser entrevistada, respondendo simpaticamente aos

nossos emails, ainda antes de chegar ao Congresso da SIEF em Lisboa, sobre o tema "People make places - ways of feeling the world", que ocorreu em abril de $2011 \mathrm{e}$ no qual ela viria a figurar como keynote speaker. ${ }^{1}$ Recebeu-nos nas instalações da Faculdade de Ciências Sociais e Humanas da Universidade Nova de Lisboa, onde tínhamos preparadas várias questões sobre sua obra e sua trajetória. Não era a sua primeira vez em Lisboa. Nesta cidade, entre convites para a participação em seminários e simpósios, Lutz tem tido a missão de nos últimos anos ser consultora científica externa em instituições como o Instituto de Ciências Sociais da Universidade de Lisboa. Em sua conferência, Lutz falou de um de seus projetos mais recentes (em colaboração com sua irmã Anne Lutz Fernandez) e que envolve o estudo das culturas automobilísticas como reprodutoras de desigualdade nos EUA. O estudo deu origem à obra Carjacked: the culture of the automobile and its effect on our lives (2010). Na conferência, primeiro fomos por ela levados às geografias e aos engenhos da globalização capitalista que faz do carro - e de todos os sistemas viários a ele associados - um dos objetos mais consumidos no contexto norte-americano. Em seguida, Lutz nos propôs interpretações das micropráticas e das percepções dos cotidianos, explorando a ideia de que o que leva boa parte dos norte-americanos a passar tanto tempo dentro de viaturas tem a ver com concepções sociais de tempo e espaço. Eles consomem frequentemente os seus carros como espaços encapsulados que os privam dos contatos complexos e heterogêneos com um mundo social que concebem como perigoso e ameaçador. É claro que não poderia faltar o paradoxo: o risco de fato surge, afinal, associado ao automóvel e a toda essa cultura que a indústria norte-americana promove desde o pós-guerra e que se expande sem cessar no mundo contemporâneo.

Nesta entrevista, Lutz nos fala sobre sua formação, expondo a importância que determinados autores e obras tiveram para a formulação de suas inquietações intelectuais, discorrendo sobre as sínteses teóricas produzidas e as cenas acadêmicas de que participava nessas ocasiões.

O estudo das emoções ganhou um forte impulso na cena antropológica norteamericana nos anos 1980. Datam dessa década trabalhos seminais, como o estudo de Lila Abu-Lughod (1986) sobre a poesia amorosa entre os Awlad 'Ali e as reflexões de Michelle Rosaldo (1984) sobre as emoções como "pensamentos incorporados", baseadas em trabalho de campo realizado junto aos llongot. 
Unnatural emotions, primeiro livro de Catherine Lutz (1988), surgiu naquela época em que se ampliava a discussão sobre as formas de construção das emoções como objeto de estudo antropológico. Nele, a autora explora as emoções entre os Ifaluk na Micronésia, esboçando a partir daí um conjunto de reflexões acerca da maneira como a experiência emocional é entendida no "Ocidente".2

O livro traz uma importante contribuição para a antropologia das emoções: a investigação minuciosa dos eixos em torno dos quais se organiza a percepção da vida emocional predominante no Ocidente em vários planos - o senso comum, o discurso acadêmico, as obras de ficção. Esta investigação é construída com base na noção de "etnopsicologia", entendida como o conjunto de ideias compartilhadas por um grupo acerca das emoções. Lutz propõe que a etnopsicologia "euro-americana" estaria estruturada em torno de duas oposições: emoção versus pensamento e emoção versus distanciamento. Em ambos os casos, haveria uma marca de gênero nestes pares de opostos, com a emoção sempre associada ao feminino e o pensamento/distanciamento associado ao masculino.

A forma de valorar estas oposições, contudo, seria distinta: quando oposta ao pensamento, a emoção é o polo negativo; se oposta ao distanciamento, ganha o sinal de positivo. Esta valoração estaria associada ao tema do autocontrole: oposta ao pensamento, a emoção seria o locus do descontrole, fazendo das mulheres seres ao mesmo tempo perigosos e frágeis. Por outro lado, na oposição ao distanciamento, o controle masculino "escorregaria" para a frieza, e a emoção seria a via de acesso para a criação de empatia para com o outro. Surge daí uma terceira ideia importante: a elaboração da dimensão moral das emoções, desenvolvida por Lutz novamente em torno da problemática do gênero, com a moral masculina sendo descrita como uma questão de aplicação de princípios abstratos a casos particulares e a moral feminina sendo marcada pela preocupação com os outros e referida a situações concretas.

Duas temáticas atravessam assim a descrição desta etnopsicologia ocidental: o gênero e o controle. Dois anos depois, Lutz organiza, em parceria com Lila Abu-Lughod, uma coletânea de estudos em antropologia das emoções intitulada Language and the politics of emotions, que guarda uma relação de continuidade com esse primeiro trabalho, ao mesmo tempo em que traz uma nova contribuição teórica.

No artigo de sua autoria aí publicado, Lutz dá prosseguimento à investigação sobre a relação entre representações da emoção e concepções de gênero, com base em um conjunto de entrevistas realizadas com homens e mulheres norte-americanos. Em sua análise, um terceiro tema vem se juntar ao gênero e ao controle: o poder. Para ela, "toda fala sobre controle emocional seria uma fala sobre o poder" (1990:70). E, comparando esses discursos sobre a emoção com o estudo de Michael Taussig (1984) sobre as relações colonizador-colonizado, Lutz conclui que "os discursos sobre a emoção podem ser um dos mais prováveis e poderosos instrumentos por meio dos quais se exerce a dominação" (1990:77, tradução nossa). É aí, então, que o tema do poder vem formar, juntamente com o gênero e o controle, uma "tríade" temática que marcará esse momento fundador.

O tema do poder dá ainda a tônica das reflexões teóricas propostas por Lutz e Abu-Lughod na "Introdução" a esta coletânea. As autoras traçam um mapeamento do campo dos estudos sobre emoções, identificando três vertentes teóricas principais: o "essencialismo" (baseado na crença na existência de uma "essência universal" das emoções); o "relativismo" (ancorado na noção de que as emoções seriam "construções culturais"); e o "historicismo", de "espírito intelectual" semelhante ao relativismo, ou seja, desconfiado da atitude essencialista, porém voltado para a análise das variações diacrônicas das emoções. 
Tendo este quadro como pano de fundo, Lutz e Abu-Lughod propõem uma quarta forma de analisar as emoções, que batizam de "contextualismo". Esta proposta teórica é baseada na noção foucaultiana de discurso, entendida como "uma fala que forma aquilo sobre o que fala". As autoras postulam a existência de discursos emocionais e de discursos sobre as emoções, advogando a ideia de que tais discursos só podem ser entendidos em relação ao contexto do qual emergem. Esta proposta guarda assim uma ligação que é tanto de continuidade quanto de refinamento no que diz respeito ao relativismo, na medida em que a "desessencialização" da emoção é, evidentemente, uma condição de possibilidade para seu entendimento contextualizado. A ênfase no contexto, contudo, faz com que as duas vertentes se afastem, a emoção perdendo, além de sua "essência", qualquer natureza fixa e estável, restrita ao self de quem a sente e para além de contextos específicos.

Este recurso a Foucault, permitindo assim pensar a emoção como um discurso, insere sua análise nas preocupações com a "micropolítica", ou seja, com o trabalho realizado pelas emoções na vida pública.

Esta síntese teórica que vincula os estudos sobre a emoção aos temas do poder e da moral atravessa a obra de Catherine Lutz, construindo uma ponte entre esses primeiros trabalhos e seus últimos estudos sobre o militarismo. Sua obra mais recente acompanha assim o movimento que vem há alguns anos ampliando o leque de objetos possíveis para a antropologia das emoções, que volta seu olhar, antes concentrado em temas associados à vida íntima/privada (tais como as relações amorosas ou de amizade e a saúde/doença), para temáticas da esfera pública, como os movimentos sociais (Goodwin; Jasper \& Polletta 2011), a violência urbana (Coelho 2010a; Jimeno 2004, 2010) ou as transformaç̃̃es em regimes políticos (Svasek 2006). ${ }^{3}$

Nesta entrevista, Lutz comenta a forma como tal preocupação teórica aparece em seu trabalho sobre os veteranos de guerra (em parceria com M. Gutmann), desenvolvendo a relação entre linguagem, nomeação e política no campo da vida emocional. Seu trabalho pode assim ser aproximado daqueles de outros estudiosos contemporâneos, tais como Judith Butler e Arthur Kleinman que, apesar de partirem de formações distintas, com ela compartilham a inquietação mais ampla acerca da desigualdade primordial que atravessa o reconhecimento social dos dramas vividos pelos indivíduos em situações de guerra.

Certas perguntas cruciais formuladas por Butler, como em que situações uma morte pode ser pranteada (2009), ou de que modo o luto e a sensibilidade às mortes são vedados a alguns em nome da sensibilidade de outros (2004), ecoam aquilo que Lutz destaca na entrevista como as disputas pelo direito de nomear as emoções. Ou mesmo configurá-las em "linguagens emocionais" no quadro da guerra. Em ambas as propostas, fica claro que a "guerra" implica também um embate político e moral crucial em torno das linguagens sobre as dores, os danos e os custos pessoais e coletivos.

As narrativas de cunho psiquiátrico teriam aqui lugar complexo, como Lutz também indica ao falar da produção de diagnósticos sobre os veteranos. De modo semelhante, Arthur Kleinman, ao trabalhar com um caso de paciente "em depressão", mostra-nos o quanto sua resistência ao tratamento - e ao próprio diagnóstico - era, antes de mais nada, fruto de uma grande crise em função da definição moral de seus atos durante a guerra, e não de seu estado clínico ou daquilo que se poderia relacionar às suas emoções pessoais. Ao lutar para ver reconhecido como assassinato um de seus atos cometidos durante os confrontos, o veterano encontrou não apenas negativas, mas uma verdadeira incongruência moral e, consequentemente, a incompreensão absoluta de sua forma de ver o mundo da guerra. $O$ que ele fizera era heroico, e não criminoso. Ou, ainda, apenas parte da rotina da guerra (Kleinman 2006:27-45).

Tal caso parece remeter diretamente ao que Lutz destaca na entrevista como 
parte dos indizíveis da guerra, não porque inconfessáveis pelos indivíduos, mas porque jamais reconhecidos em sua dimensão profundamente moral. A profusão de diagnósticos teria também, nesse sentido, efeito de silenciamento dessas angústias e desses dilemas morais, apartando o plano das supostas consequências pessoais da guerra de sua dimensão política maior. Em outro nível, tal silenciamento atingiria, como Butler também apontou, a própria possibilidade de discutir o militarismo e a gigantesca maquinaria norte-americana de guerra. Ao contrário do contexto da guerra do Vietnã, que Lutz viveu muito jovem ainda, marcado pelas disputas abertas em torno dos significados e da legitimidade do confronto, no cenário contemporâneo imediato impera a produção de uma aquiescência não apenas sobre os conflitos militares em curso, mas sobre a própria reprodução institucional gigantesca e cotidiana dentro dos EUA.

Apesar de sempre ter existido oposição generalizada entre os antropólogos em relação às guerras que nos envolveram emocionalmente nos últimos anos, isto não tem implicado senão o seu engajamento tímido e desconfortável, como aponta Robben (2009) no editorial da revista Anthropology Today. A questão, segundo o autor, é que tais sentimentos, ao contrário do que seria de esperar, não se traduziram em protestos políticos. Este recuo quanto ao engajamento provocado pela guerra do Vietnã pode ser explicado de múltiplas formas, mas o apertado cerco moral da parte dos governos, alegado por razões de segurança, e do silêncio em virtude de um bem maior - patriótico ou humanitário têm reduzido as vozes dos antropólogos e a complexidade do que estes podem dizer na esfera pública, como bem adverte Butler (2004). Outro aspecto mais concreto passa pela contratação de antropólogos pela CIA e comissões militares dos EUA, algo que não chegou a ser frontalmente contestado pelos representantes das maiores associações de antropólogos norte-americanas, nomeadamente a AAA. Exceção à regra, Catherine Lutz, acompanhada por antropólogos como William Beeman, Roberto González, Hugh Guterson, David Price e o próprio Marshal Sahlins, tem falado publicamente e assumido com coragem uma posição contra as guerras. Tais posicionamentos contribuem para evidenciar a imensa tragédia e a forma como recursos materiais, humanos e simbólicos vêm sendo despendidos em nome da guerra pelo governo norteamericano e outros governos do mundo.

Mas ao colocarmos em perspectiva a obra de Lutz, compreendemos mais claramente o impacto de sua contribuição intelectual. Em seu já mencionado trabalho em parceria com Matthew Gutmann, Breaking ranks: Iraq veterans speak out against the war (2010), a autora permitese testar formas narrativas da etnografia, abrindo o campo de difusão do saber antropológico em sentidos imprevistos. Lutz talvez se aproxime daquilo que Van Maanen recentemente apelidou de advocacy tales (2010). Este tipo de narrativa etnográfica que não esconde o seu engajamento, tradição das teorias críticas, tem um lugar no mundo da antropologia, sobretudo a norte-americana. Veja-se também o notório exemplo de Hugh Gusterson (1996) e do seu retrato aterrador da indústria de design de armas dos EUA. No mesmo sentido, surge o trabalho de Teresa Caldeira (2003), ao combinar a análise da violência cotidiana e a falência institucional na cidade de São Paulo dos anos 80 e 90 . Com estas novas formas narrativas os temas da antropologia das emoções, da antropologia política e das instituições articulam-se através de uma série de coordenadas teóricas, empíricas e estilísticas sem precedentes. Catherine Lutz é seguramente uma das acadêmicas que mais têm contribuído para tal.

Maria Claudia Coelho Susana Durão Adriana Vianna 


\section{Notas}

${ }^{1}$ A entrevista foi concedida a Maria Claudia Coelho, professora do Departamento de Ciências Sociais - UERJ (mccoelho@bighost. com.br) e Susana Durão, investigadora auxiliar do Instituto de Ciências Sociais da Universidade de Lisboa (ssbdurao@gmail.com). Transcrição da entrevista: Thaddeus Blanchette. Tradução: Maria Claudia Coelho.

2 Lutz define como "euro-americanas" as concepções acerca da experiência emocional a que aqui nos referimos como "ocidentais".

${ }^{3}$ Para uma discussão sobre a emergência destes novos objetos de pesquisa no campo da antropologia das emoções, ver Coelho (2010b).

\section{Referências bibliográficas}

BUTLER, Judith. 2004. Precarious life: the powers of mourning and violence. London/New York: Verso.

_. 2009. Frames of war: when life is grievable? London/New York: Verso.

CALDEIRA, Teresa. 2003. Cidade de muros. Crime, segregação e cidadania em São Paulo. São Paulo: Ed. 34/Edusp.

COELHO, Maria Claudia. 2010a. As emoções e a ordem pública: uma investigação sobre modelos teóricos para a análise socioantropológica das emoções.

Trabalho apresentado na $27^{\text {a }}$. Reunião Brasileira de Antropologia, realizada entre os dias 01 e 04 de agosto de 2010, Belém, Pará, Brasil. Ms. 2010b. "Narrativas da violência: a dimensão micropolítica das emoções". Mana - Estudos de Antropologia Social, 16(2):265-285.

GOODWIN, J.; JASPER, J. M. \& POLLETTA, F. (orgs.). 2001. Passionate politics emotions and social movements. Chicago and London: University of Chicago Press.
GUSTERSON, Hugh. 1996. Nuclear rites: a weapons laboratory at the end of the Cold War. Berkeley: University of California Press.

GUTMANN, Matthew \& LUTZ, Catherine. 2010. Breaking ranks: Iraq veterans speak out against the war. Berkeley: University of California Press.

JIMENO, Myriam. 2004. Crimen pasional contribución a una antropología de las emociones. Bogotá: Universidad Nacional de Colombia.

_. 2010. "Emoções e política: a vítima e a construção de comunidades emocionais." Mana - Estudos de Antropologia Social, 16(2):99-121.

KLEINMAN, Arthur. 2006. What really matters. Living a moral life amidst uncertainty and danger. Oxford/New York: Oxford University Press.

LUTZ, Catherine \& FERNANDEZ, Anne Lutz. 2010. Carjacked: the culture of the automobile and its effect on our lives. New York: Palgrave Macmillan. ROBBEN, Anthonius. 2009. "Anthropology and the Iraq War. An uncomfortable engagement. Guest editorial". Anthropology Today, 25(1):1-3.

SAHLINS, Marshall. 2009. "Te teach-ins: antiwar protest in the Old Stoned Age. Guest editorial". Anthropology Today, 25(1):3-5.

SVASEK, Maruska (org.). 2006. Postsocialism politics and emotions in Central and Eastern Europe. New York: Berghahn Books.

VAN MAANEN, John. 2010. "A song for my supper. More tales of the field". Organisational Research Methods, 13(2):240-255. 
Susana Durão: Como começou o seu interesse pela antropologia?

Eu costumava ler a National Geographic na época em que morava em um subúrbio de Nova York. Eu era adolescente e a região era muito homogênea, com uma população predominantemente branca. Acho que o choque do exótico moldou a minha aproximação com essa disciplina. Ver aquela revista me fez perceber que o mundo era muito mais colorido do que eu imaginava. E a National Geographic tem uma visão muito positiva do resto do mundo, por isso acho que fui realmente apresentada ao campo através desta revista de uma maneira muito marcante. Mas também teve importância a experiência social de tentar entender o que mais havia lá fora.

Acho que uma outra razão está relacionada à Guerra do Vietnã. Crescer em meio à turbulência dos anos 60 nos Estados Unidos e ter, tanto dentro da minha família quanto na comunidade mais ampla, esses conflitos de valores. As pessoas discutiam - muito raivosamente-por causa das profundas divisões em torno da guerra. Ao mesmo tempo, tudo estava mudando nos Estados Unidos: o movimento feminista, os direitos civis, todas essas mudanças. Essas brigas aconteciam também dentro da minha família - se essas mudanças culturais e essas instituições políticas eram corretas. Acho que eu pensava que a antropologia, na época em que eu fui para a faculdade e a descobri, era uma maneira de entender como as pessoas podiam pensar de formas tão diferentes e ainda assim serem pessoas boas e humanas, como meu pai e minha mãe. Era e é importante para mim não desumanizar a diferença nos conflitos políticos, os atores nos conflitos políticos. Acho que eu apreciava isso, que a antropologia oferecesse um caminho para evitar isso. E a ideia de que há formas alternativas de viver que a antropologia pode nos apresentar, e se há diferenças sociais e políticas em outros lugares, há sociedades que talvez tenham formas de resolver as coisas, e que são de, algum modo, menos injustas. Bom, tudo isso era uma boa notícia. Eu entendi a antropologia como geradora de uma mensagem otimista nesse sentido.

Eu fui apresentada à antropologia através da antropologia psicológica. Meu primeiro professor foi Steven Piker - ele era desta linha. Foi por esse caminho que entrei na pós-graduação. Fui trabalhar em Harvard com John Whiting, que também trabalhava nesta área e era um dos nomes principais. Os pós-estruturalistas haviam chegado a Harvard, onde eu estava fazendo minha pós-graduação. Então, essa combinação da antropologia psicológica com o pós-estruturalismo produziu Unnatural emotions, que foi minha tese de doutorado e meu primeiro livro, que é uma desconstrução da ideia de "psicológico", da noção de uma vida emocional humana universal. Acho que isso é bastante previsível: quando você aproxima duas grandes vertentes teóricas ou paradigmas, os estudantes muitas vezes produzem algo que é um novo amálgama dos dois.

SD: A antropologia cognitiva estava muito desenvolvida nos anos 90. De que forma você vê, olhando retrospectivamente, essa forma de reaproximação entre a psicologia e a antropologia?

Sim, essa era uma das coisas que estavam acontecendo na época da minha formação. A revolução cognitiva havia acontecido e estava chegando à antropologia, após ter reorganizado a psicologia. Ela chegou à disciplina de várias formas. Nos anos 80, eu havia tido contato com psicólogos que estavam interessados, a partir de uma perspectiva cognitivista, 
no que a antropologia tinha a dizer sobre as emoções, porque, é claro, estavam tentando programar emoções usando um tipo muito racionalista de modelo do pensamento humano no mundo da inteligência artificial. Assim, a ideia de introduzir emoções seria esta coisa nova e revolucionária que iria tornar o computador realmente humano.

Acho que esta influência cognitivista estava muito entranhada no que eu estava fazendo. Uma das críticas feitas aos meus primeiros trabalhos foi de que eles eram em alguma medida "desencarnados" e de que talvez faltasse algo do aspecto psicodinâmico... Mesmo apreciando de fato essa literatura e tendo lido muito nessa área, vindo de uma tradição freudiana (e também da crítica feminista), acho que ao final das contas segui em uma direção diferente. Tentei de fato apenas lidar com aquela pergunta original: "E se imaginássemos a emoção e a cognição de forma menos dualista?". Se questionássemos essas categorias e os tipos de nós analíticos com que nos prendemos quando tentamos distinguilas como um tipo de coisa ao invés de encará-las como discursos com os quais as pessoas tentam fazer coisas? O que as pessoas estão tentando fazer ao identificarem algo como emocional em oposição a racional ou cognitivo? Quais são as ambições ou os conflitos políticos gerados por isto e qual o seu propósito?

SD: Que tipo de incentivo intelectual você recebeu nos Estados Unidos quando era estudante? Quais foram suas influências principais? Quem você teria gostado de conhecer e de ter tido chance de trocar ideias?

Nossa, acho que tem tanta coisa para dizer sobre isso. Eu vinha desta tradição em que eu dedicava muito tempo a conversar com as pessoas da área de antropologia psicológica, tentando refazer, remodelar um pouco a discussão de que havia um ser humano "essencial" - onde a cultura ainda permanece somente como o significado que é desenvolvido na moldura da psicodinâmica humana universal. Mas aí os autores que eu estava lendo, os que mais me interessaram nos anos 80 foram Michel Foucault, a crítica do Writing culture sobre a ideia de que podíamos repensar nossa própria disciplina como uma produção histórica - eu já estava fazendo isso com a crítica da psicologia, mas queria levá-la mais a fundo na antropologia, dizer que não somos imunes aos tipos de limites culturais e aos enquadres políticos que eu estava descobrindo na psicologia enquanto campo - e Eric Wolf, que eu também estava lendo, que começou a tentar contar uma história mais ampla na qual algumas narrativas eram apagadas - as narrativas dos grupos que "não têm história". Eu tive esse tipo de experiência clássica de trabalho de campo, de ir para uma ilha e aí achar que estava olhando para uma espécie de sistema cultural. Eu estava tentando reposicionar essa história.

Maria Claudia Coelho: No seu livro Unnatural emotions esta noção de "construção cultural das emoções" parece ser central para a discussão da etnopsicologia americana. Como você vê as continuidades e as descontinuidades entre esta abordagem teórica e a perspectiva contextualista, a antropologia das emoções que você desenvolveu em Language and the politics of emotions?

Eu não as vejo como opostas, mas sim como complementares. Nesse meio tempo, li Foucault de forma mais extensa, questionei mais alguns daqueles problemas mais amplos. Meu ensaio publicado na Cultural Anthropology em 1986 foi uma tentativa de indagar sobre aqueles 
contextos maiores do pensamento euroamericano e de ir além do tipo de comparação e contraste cultural entre os modos de pensar norte-americano e ifaluk sobre as emoções, e de me colocar algumas questões mais gerais... de indagar sobre os contextos mais amplos da vida emocional, que são políticos e econômicos. Esses trabalhos foram publicados muito próximos: apenas dois anos de intervalo. Penso neles como muito próximos em termos do que eu estava tentando fazer. Repensei e reescrevi muito da minha tese original, que era bem mais limitada quanto às formas de refletir sobre os temas ligados à linguagem.

MCC: Em Unnatural emotions, a temática do gênero já está presente, principalmente quando você discute a etnopsicologia euro-americana. E dois anos depois o seu texto publicado em Language and the politics of emotion se chama "emoções generificadas" (engendered emotions). Isto sugere algum tipo de continuidade? Porque neste texto a temática do poder em relação com o gênero é muito forte.

Bem, sim. Naquela época, na década de 80, eu estava trabalhando na State University of New York at Binghamton e havia um grupo de feministas maravilhoso, muito forte, como Margaret Conkey, Joan Smith e Jane Collins, com quem mantive muitas conversas. Acho que foi daí que veio esse movimento tão forte de trazer isso inteiramente para a linha de frente.

MCC: No seu livro Reading national geographic há uma passagem na qual você discute a reação de uma professora norte-americana às preocupações de seus alunos quanto ao sofrimento das crianças no Iraque devido à guerra. A professora diz a eles que não se preocupem porque isto está acontecendo muito longe e que por isso eles não se machucariam. Você vê relação entre esta passagem e a emergência do seu interesse pelo militarismo como um objeto de pesquisa?

Com certeza. Claro. Você sabe, o fato de que nós havíamos começado esse projeto sobre a National Geographic e aí vem essa guerra, certo? O que realmente traz à tona a questão de como é possível que uma produção cultural popular como essa, que é tão popular, que está lá fazendo seu trabalho, criando uma visão positiva do mundo e por aí vai... Como é possível que estas duas nações possam entrar em guerra? Que os Estados Unidos possam levar seu povo à guerra sem maiores protestos (risada irônica). Então, acho que isso realmente aguçou a minha percepção não apenas do que estava acontecendo com a National Geographic em particular - seu evolucionismo social, no fundo, é uma espécie de imperialismo amistoso - mas tornou claro que a revista não estava questionando algumas noções básicas sobre desigualdade e poder no mundo.

Mas o meu interesse pela ética militarista de fato remonta à época da Guerra do Vietnã. Ver essas imagens na televisão e ter uma percepção gráfica de como a guerra é horrível. Meu pai foi do exército. Ele lutou na Segunda Guerra e foi também um veterano da Guerra da Coreia e, em seguida, ficou muitos anos na reserva. Então, durante a Guerra do Vietnã, uma vez por mês ele vestia o uniforme e ia para o seu posto de serviço. Minha mãe era uma pessoa crítica em relação à guerra, com base na teoria da guerra, mas basicamente tínhamos essa discussão em casa sobre se essa guerra era uma boa ideia. Acho que parte do meu interesse pelo militarismo vem desse início precoce. Mas nunca levei isso adiante porque não parecia ser um objeto de estudo: parecia mais objeto de 
uma ansiedade enorme (risada). E um objeto de trabalho político. De algum modo, eu ainda não havia integrado isso plenamente em minha concepção de antropologia, de que há uma política da emoção. Mas é possível estudar de fato algo que está no âmago de uma coisa que, no mundo contemporâneo, é ainda realmente indizível?

Uma crítica ao militarismo nos Estados Unidos ainda é, hoje, indizível. Mesmo hoje, acho que falo de um lugar situado nas margens da vida política. O que digo é quase incompreensível para muitas pessoas. "O que há com você?" [risada]. Então eu acho que... eu só me aproximei disso mais tarde. Eu estava na Carolina do Norte (me transferi para a UNC, University of North Carolina at Chapel Hill) e disse: "Acho que meu próximo projeto aqui, bem, quero estudar os militares". Era o fim da Guerra Fria, em meados dos anos 90. Parecia que a guerra havia terminado, mas eu percebia que não: ainda havia esse imenso aparato militar. Por isso comecei meu projeto lá. Fort Bragg fica a uma hora e meia do meu escritório em Chapel Hill. A base estava bem ali e, da primeira vez em que a vi, eu disse: "Poxa! Ok. É isso que eu tenho que fazer". Era um entre mil lugares existentes na paisagem americana que são invisíveis para a maioria das pessoas: esta rede de bases militares em que a preparação para a guerra continua dia a dia. Então eu disse: "Quero entender isso". A parte oculta e rotinizada disso tudo. Oculta e rotinizada. A reprodução institucional rotinizada. É gigantesco: o orçamento anual do Exército americano é de 1 trilhão de dólares. Inclui fontes variadas em meio aos gastos federais.

SD: Impressionante. Então você tinha dois problemas para resolver: o militarismo na antropologia e o militarismo como o assunto de uma nação.
Sim! Exatamente isso (risada). A princípio não havia ninguém com quem conversar. Havia alguns sociólogos, mas que tendiam a ser sociólogos militares que estavam trabalhando, e que muitas vezes eram até mesmo financiados pelo exército americano. Eles muitas vezes fazem esse trabalho.

MCC: No seu trabalho com Matthew Gutmann sobre veteranos de guerra e o diagnóstico psiquiátrico da síndrome do estresse pós-traumático, você discute o trabalho moral feito na esfera pública norte-americana pela recusa dos soldados veteranos em aceitar este diagnóstico, sugerindo, em vez disso, um entendimento deste sofrimento como algo normal em situações que poderiam, elas mesmas, ser descritas como patológicas. Existe alguma relação entre esta forma de interpretar o sofrimento dos soldados proposto pelo movimento IVAW e o conceito de "micropolítica das emoções" discutido em Language and the politics of emotion?

Com certeza. Nunca parei de procurar as linguagens emocionais, certo? Então, com este projeto sobre os veteranos, mas também com o projeto sobre o carro, estive interessada na política das emoções, definitivamente a noção de que há uma disputa em torno de quem detém o direito de nomear estas emoções, o que se quer dizer quando se tem uma reação emocional à guerra. E existe algum lugar mais importante para o Estado estar envolvido? Então, há financiamentos enormes para a pesquisa sobre a síndrome do estresse pós-traumático e não dá para não encarar isso como uma tentativa, no nível macro, de estruturar a discussão sobre a política das emoções associadas com o ir para a guerra e a ideia de que estas são "feridas de guerra", de que são feridas psiquiátricas. Quero dizer, os soldados também 
definiram isto como uma agenda, porque não querem que isso seja ignorado, certo? Mesmo que tenha sido um movimento dos veteranos da época da Guerra do Vietnã que conseguiu que esta síndrome fosse reconhecida, que fez com que essas feridas psíquicas fossem reconhecidas, a ideia de que você não está se fingindo de doente... O estrago feito pela guerra nem sempre é físico. Então, essa foi uma conquista de um movimento político. Por outro lado, ver em seguida a forma como isso esvaziou a dimensão política da discussão sobre a guerra é o que o IVAW está questionando. Eles são dissidentes de um movimento mais amplo em favor da definição da síndrome do estresse pós-traumático como uma ferida psiquiátrica e fim da história, em oposição a fazer com que esta síndrome levante as questões morais e políticas que eles sentem, no fundo da alma, que são o que está em jogo; que eles participaram de coisas horríveis e que, entre outras coisas, há aspectos morais com os quais eles nunca poderão fazer as pazes; quem eles mataram ou quem eles viram ser morto. Isto não inclui apenas civis, mas seus próprios amigos e outros temas, como a culpa e a ansiedade quanto a se fizeram ou não o suficiente. Parte disso é incentivada pela noção de que seu dever básico como soldado é para com os seus companheiros de armas, e parte da armadilha emocional que há aí vem do treinamento básico em torno da ideia de que, se alguma coisa dá errado, a culpa é sua. Você tem que assumir uma parte da responsabilidade por não ter salvo a vida do homem a seu lado. Vocês todos são enviados pelo Estado para fazer este trabalho de invadir outro Estado cuja relação com você era...

SD: Em seus trabalhos, de que forma você vê a conexão entre "moralidade" $\mathrm{e}$ "emoções" (às vezes em relação, às vezes em oposição, por assim dizer)?
Estou agora mesmo escrevendo um texto sobre a moral da guerra para um volume sobre etnologia e moral e voltei àquele texto de 1986 (que também é um dos capítulos de Unnatural emotions). E lá havia uma discussão sobre moral. Mas me lembrei desta ideia sobre as contradições, como você disse. Moral, por um lado, é a antítese da natureza primeva, física, quase impulsiva das emoções, certo? Por outro lado, é a fonte do valor. A racionalidade técnica do cognitivo é destituída de qualquer sentido moral. É preciso aquele senso de indignação justificada ou de compaixão ou do que quer que seja para tornar morais, por sua vez, as capacidades humanas. Então, esta tensão sempre esteve ali.

\section{MCC: Enquanto uma antropóloga norte-} americana que já participou de processos de avaliação de instituições acadêmicas portuguesas, o que você destacaria como traços específicos das cenas antropológicas lusófonas?

Eu só estive lá por alguns dias, em encontros e conversas com antropólogos portugueses. Mas o que realmente me impressionou nesta avaliação externa foi a ideia de que há um tipo de antropologia de enorme energia colaborativa. Se você examinar os periódicos de antropologia americanos, você vai ver que a norma ainda é a autoria individual. Em geral, as disciplinas, os financiadores nos Estados Unidos estão há anos tentando incentivar o trabalho em colaboração, em equipe, interdisciplinar, mas, conforme você mencionou, realmente as barreiras entre as disciplinas são tão fortes e tão naturalizadas que ainda é difícil ver esse processo deslanchando. Quero dizer, isso tem que acontecer, mas... Acho que os portugueses já avançaram mais nisso. Talvez seja a estrutura da instituição. Neste instituto de pesquisa que eu ava- 
liei, eles trazem todos esses pesquisadores de outras disciplinas, têm dinheiro e montam os projetos de determinadas maneiras. Não sei exatamente como isso acontece, mas parece ser mais bem sucedido em derrubar as fronteiras. Mas posso estar errada (riso).

MCC: No Brasil, a sociologia e a antropologia muitas vezes estão juntas na forma como os departamentos e os programas de pós-graduação são constituídos. Esse movimento às vezes aparece em uma espécie de emparelhamento das abordagens sociológica e antropológica em relação ao mesmo objeto de estudo, ao contrário do que acontece nos Estados Unidos, em que as fronteiras disciplinares são muito mais claras. Como você vê a relação - se é que ela existe - entre a antropologia e a sociologia das emoções?

Quando eu era membro da ISRE, a Sociedade Internacional de Pesquisa sobre Emoções, havia sociólogos, psicólogos, antropólogos e historiadores envolvidos somente europeus e americanos (não sei se ainda é assim). Mas não tenho tido muito contato com eles. Mas na época havia ótimas conversas com os sociólogos e... era um tipo de sociologia histórica e microssociologia que eu achava muito interessante e apropriada.

SD: Qual é a importância da pesquisa interdisciplinar segundo o estilo antigo nos dias de hoje, com todas as transformações no campo da ciência e da produção de conhecimento? Há esta urgência em se conseguir verbas de pesquisa. O que isto significa para a antropologia?

Isto é perturbador no sentido de que as universidades cada vez mais buscam financiamentos junto à iniciativa privada. O custo de uma universidade e as anuidades aumentaram tanto... mas os salários subiram também e todos participamos desse processo. Há cada vez mais e mais trabalho a ser feito no lado financeiro das coisas com o qual você tem que se envolver ou se sente compelido a se envolver. É preciso conseguir dinheiro, seja junto às estruturas mais tradicionais, como a National Science Foundation e as fontes do governo federal ou fundações como a Wenner Gren Foundation, seja junto a essas novas fontes que estão surgindo, tais como doações particulares ou corporações privadas. E a crítica está obviamente bem desenvolvida: a ideia de que há uma mercantilização da universidade. E que o trabalho interdisciplinar, na medida em que ele vende bem junto a esses novos patrocinadores, tem essa estrutura de isenção de impostos, creio. Acho que nem sempre é assim. Mas ainda temos essas tradições diferentes de disciplinas mais ou menos críticas, de que a antropologia é algo meio inócuo. Acho que podemos dizer que a antropologia e a ciência política não têm necessariamente a mesma orientação cética em relação ao Estado: um ceticismo profundo versus a questão de, você sabe, "Diga-nos como ajudar. Onde assino?". Acho que isso é um estereótipo, mas ainda reconhecemos essas tendências diferentes e isso às vezes é variável, às vezes útil na orientação interdisciplinar: "Vamos nos juntar pra fazer isso, podemos cada um trabalhar em um pedaço". Não tenho certeza quanto ao resultado final. O resultado final é às vezes uma espécie de solução de compromisso.

SD: Na sua opinião, qual poderia ser o papel principal da antropologia no futuro próximo?

Bem, acho que a antropologia ainda esboça de forma única este quadro contextualizado que está sempre recuando um passo e dizendo que há algo maior 
e mais sistêmico em jogo. Há algo que não podemos ver - cultural, histórica ou politicamente - com o rosto colado no presente, nas poderosas instituições que estruturam o conhecimento. Somos capazes de, em alguma medida, fazer esse trabalho de crítica. Isto nos vem mais prontamente e temos diversos instrumentos de crítica que nem todas as outras disciplinas têm. E, mais uma vez, o ponto é de certa forma questionar essas fronteiras que construímos em torno das disciplinas e dos departamentos ao invés de construí-las em torno de um projeto, o que poderia ser igualmente vitalizante, desenvolvido e rico metodologicamente.

SD: Na sua opinião, qual o espaço da antropologia no Watson Institute?

O Watson Institute é um centro interdisciplinar. Acho que o Watson Institute é muito particular. Muitas pessoas que vêm de outros centros de estudos internacionais apontam isto: "Nossa! Vocês têm tantos antropólogos aqui!". E temos historiadores; acabamos de contratar um historiador este ano como um de nossos principais pesquisadores. Acho que, de certa forma, essa é a "marca Watson", embora eu deteste nos transformar em uma mercadoria. É a nossa marca no mercado intelectual. Estou lá há oito anos.

SD: Você acha que no Watson Institute você tem liberdade para pensar como uma antropóloga, a liberdade intelectual de fazer críticas?

Mas lá, no Watson Institute, eu realmente encontro espaço para "pensar" como uma antropóloga e olhar criticamente. Desenvolvi um projeto lá com Neta Crawford, da Boston University, chamado "Os Custos do Projeto de Guerra", que está em preparação para o décimo aniversário da reação militar ao 11 de Setembro. Reunimos cerca de 20 pesquisadores de diversas disciplinas e tentamos dizer "Vamos pesquisar a guerra inteira. O que sabemos sobre os custos financeiros, humanos, políticos, sociais?". O relatório recebeu um bocado de atenção da mídia e temos um website muito elaborado (www.costsofwar.org) à disposição de jornalistas e outras pessoas para pesquisarem quando escreverem suas histórias sobre as guerras. Espero que todos alcancem uma visão mais crítica e integral diante do público, ao invés de apenas medo e celebração do heroísmo.

SD: Como você lida com este sentimento, esta emoção? Porque este tema é inegavelmente muito delicado.

Bem, você sabe, "trabalhe duro e siga em frente". Que emoções? (riso)

SD: Alguém tem que fazer isso, certo?

Certo. Esta é a minha teoria. 
Mana. Estudos de Antropologia Social

\section{ERRATA}

No volume 18 n 1, pp. 213-224: Entrevista com Catherine Lutz, foram feitas as seguintes alterações:

Autoria do texto introdutório à entrevista: Maria Claudia Coelho, Susana Durão e Adriana Vianna.

A transcrição da entrevista foi feita por Thaddeus Blanchette e sua tradução por Maria Claudia Coelho. 